\title{
Letters
}

\section{Anaemia in rheumatoid arthritis}

SIR, The unreferenced assertion by Farah, Sturrock, and Russell that iron deficiency anaemia is a common feature of rheumatoid arthritis and is often caused by an asymptomatic peptic ulcer ${ }^{1}$ should not go unchallenged. The diagnosis of iron deficiency in patients with inflammatory disease is difficult, unless bone marrow estimations of iron stores are performed. Perhaps the authors would care to support the statement regarding the prevalence of iron deficiency in rheumatoid arthritis with a suitable reference.

In our experience upper gastrointestinal lesions, including asymptomatic peptic ulceration, are common in patients taking non-steroidal anti-inflammatory drugs and are found no more frequently in patients whose anaemia is microcytic, or those with positive faecal occult bloods, than in those with a normocytic anaemia or negative faecal occult bloods. ${ }^{2}$ This observation together with other evidence $^{3}$ strongly suggests that upper gastrointestinal lesions are not the cause of iron deficiency when it does occur in rheumatoid arthritis. The mere coincidence of two abnormalities does not imply any causal association.

Royal National Hospital

ALAN DOUBE

for Rheumatic Diseases,

Upper Borough Walls,

Bath BA1 1RL

\section{References}

1 Farah D, Sturrock R D, Russell R I. Peptic ulcer in rheumatoid arthritis. Ann Rheum Dis 1988;47:478-80.

2 Doube A, Collins A J. Anaemia in patients with arthritis: Are simple investigations helpful? Br J Rheumatol (in press).

3 Doube A. Anaemia and non-steroidal anti-inflammatory drugs. Br J Rheumatol 1988;27:247-8.

SIR, We were interested to read Dr Doube's comments on our paper with respect to asymptomatic peptic ulcers causing iron deficiency anaemia. We would certainly agree with him that asymptomatic peptic ulceration is common in patients taking non-steroidal anti-inflammatory drugs but we would emphasise that the gold standard for diagnosing iron deficiency in a rheumatoid patient is a bone marrow examination. ${ }^{1}$ In our experience the measurement of faecal occult bloods is a very unreliable test of blood loss from gastrointestinal lesions. In a recent study of 58 patients with rheumatoid arthritis who underwent endoscopy for iron deficiency anaemia we found that $55 \%$ had upper gastrointestinal lesions, and after treatment for these the anaemia resolved in 20 patients. Twelve patients with normal upper gastrointestinal endoscopy results had a positive faecal occult blood test.
As far as our practice is concerned $40 \%$ of patients with rheumatoid arthritis with anaemia were iron deficient. $\frac{\overline{5}}{5}$

University Department of Medicine

R D STURROCK

Royal Infirmary,

10 Alexandra Parade,

Glasgow G31 2ER

\section{References}

1 Zoma A, Hambley H, Sturrock R D. Prediction of marrow irop stores in serum ferritin levels. Br J Rheumatol 1987;26:36. $\stackrel{\oplus}{\infty}$

\section{Absence of an association between ankylosing spondylitis and $\operatorname{IgA}$ nephropathy}

SIR, In their recent article Peeters et al reported on IgA containing immune complexes in ankylosing spondylitis. They stated that ankylosing spondylitis is associated with IgA nephropathy. This statement is not based on epiden logical studies, however, but on reports of the co-occurre of ankylosing spondylitis and IgA nephropathy. Wall et aP described an increased incidence of recurrent haematurian in 32 patients with ankylosing spondylitis, but in only onep patient was the diagnosis of IgA nephropathy confirmed. The report by Jones et al also showed an increase incidence of recurrent haematuria in patients with anky3 losing spondylitis ${ }^{3}$ : in only one of 51 patients was the diagnosis $\operatorname{IgA}$ nephropathy proved. Swaak et al found no.?. evidence of $\operatorname{IgA}$ nephropathy in any of $\mathbf{4 0}$ patients with ankylosing spondylitis. ${ }^{4}$ Likewise, Calin reported the absence of any evidence of IgA nephropathy in 68 patients suffering from ankylosing spondylitis. ${ }^{5}$ From these studies. it can be concluded that recurrent haematuria occurs in up to $20 \%$ of patients suffering from ankylosing spondylitis whereas $\operatorname{IgA}$ nephropathy proved by biopsy is present in about $2 \%$.

The prevalence of IgA nephropathy in general popula tions is estimated to be between 0.2 and $4 \%{ }^{6}$ Thus studies. of larger populations of patients with ankylosing spondylitis, are needed to judge the real prevalence of IgA nephropath ${ }^{\prime}$ in this disease.

Recently, we reviewed the data from 276 consecutive patients with ankylosing spondylitis (New York criteriaf seen at our outpatient clinic between 1984 and $198 \%$ Twenty five patients had recurrent haematuria (more that one observation of $\geqslant 10$ red blood cells per high powe field). In seven patients the haematuria did not reappear during follow up. In eight patients another explanation for haematuria was found (renal stones twice; urinary trao. infections five times; malignant tumour of the kidne once). In five patients recurrent haematuria persisted ove 
Table 1 Clinical findings in five male patients with ankylosing spondylitis and IgA nephropathy

\begin{tabular}{|c|c|c|c|c|c|}
\hline & 1 & 2 & 3 & 4 & 5 \\
\hline Age & 57 & 62 & 26 & 52 & 41 \\
\hline $\begin{array}{l}\text { Duration of } \\
\text { haematuria } \\
\text { (years) }\end{array}$ & $1 \cdot 5$ & 12 & 5 & 36 & 5 \\
\hline $\begin{array}{c}\text { Proteinuria } \\
(g / 24 \mathrm{~h})\end{array}$ & $0 \cdot 5$ & $0 \cdot 5$ & $0 \cdot 5$ & $1 \cdot 0$ & $1 \cdot 0$ \\
\hline $\begin{array}{l}\text { Serum } \\
\text { creatinine } \\
(\mu \mathrm{mol} / \mathrm{l}) \\
\text { IgA }(\mathrm{IU} / \mathrm{l})\end{array}$ & 80 & 105 & 81 & 132 & 104 \\
\hline $\begin{array}{c}(\text { normal } \leqslant 225) \\
\text { Intravenous }\end{array}$ & 288 & 300 & 240 & 340 & 340 \\
\hline $\begin{array}{l}\text { Intravenous } \\
\text { pyelography }\end{array}$ & Normal & Normal & Normal & Normal & Normal \\
\hline Purpura & & - & - & - & - \\
\hline $\begin{array}{l}\text { Cystoscopy } \\
\text { Skin biopsy }\end{array}$ & Normal & Normal & Normal & Normal & Normal \\
\hline $\begin{array}{l}\text { Skin biopsy } \\
\text { Kidney biopsy }\end{array}$ & ND* $^{*}$ & ND & ND & Normal & Normal \\
\hline Kidney biopsy & ND & ND & ND & ND & $\operatorname{IgA}^{*}$ \\
\hline
\end{tabular}

${ }^{*} \mathrm{ND}=$ not done $; \operatorname{Ig} \mathrm{A}=$ mesangial proliferation and $\operatorname{Ig} \mathrm{A}$ depositions.

several years. The absence of macroscopic haematuria, proteinuria, and purpura in combination with normal renal function and serum IgA makes the diagnosis IgA nephropathy unlikely in these five patients.

In three patients we considered IgA nephropathy was possible by exclusion of other causes of haematuria. It is likely that in one patient with Henoch-Schönlein purpura haematuria was caused by IgA nephropathy. In one patient IgA nephropathy was proved by kidney biopsy (see Table 1). So in this population of patients with ankylosing spondylitis the prevalence of IgA nephropathy was between $0.3 \%$ (proved by kidney biopsy) and $1.8 \%$. The estimated prevalence of IgA nephropathy in Holland is $0.2-0.9 \%$, based on a single determination of proteinuria, which is a less sensitive parameter than recurrent haematuria. ${ }^{6}$

In conclusion, we did not find support for the hypothesis that the prevalence of IgA nephropathy in Dutch patients with ankylosing spondylitis is greater than that in the general population. Therefore we want to stress that the existence of an association between ankylosing spondylitis and IgA nephropathy is not yet proved. Although it is tempting to assume a pathogenetic relation when two rare diseases, both associated with IgA, occur in one patient, one should be careful to base such a relation on case reports.

\footnotetext{
${ }^{1}$ Department of Rheumatology, Jan van Breemen Institute, dr Jan van Breemenstraat 2, 1056AB Amsterdam, The Netherlands

M A F J VAN DE LAAR 12 H J BERNELOT MOENS ${ }^{13}$ J K VAN DER KORST ${ }^{12}$

${ }^{2}$ Department of Rheumatology, Academisch Medisch Centrum, University of Amsterdam, Meibergdreef 9, 1105AZ Amsterdam

${ }^{3}$ Department of Rheumatology, Academisch Ziekenhuis, Free University, de Boelenlaan 1117, 1081 HV Amsterdam
}

\section{References}

1 Peeters A J, van den Wall Bake A W L, van Dalsen A D, Westedt M-L. Relation of microscopic haematuria in ankylosing spondylitis to circulating IgA containing immune complexes. Ann Rheum Dis 1988; 47: 645-7.

2 Wall B A, Agudelo C A, Pisko E J. Increased incidence of recurrent hematuria in ankylosing spondylitis: a possible association with IgA nephropathy. Rheumatol Int 1984; 4: 27-9.

3 Jones D W, Mansell M A, Samuell C T, Isenberg D A. Renal abnormalities in ankylosing spondylitis. Br J Rheumatol 1987; 26: $341-5$.

4 Swaak A J G, Frankfort I, Menon R S, Pekelharing J M, Planten $O$. Absence of IgA nephropathy in patients with ankylosing spondylitis. Rheumatol Int 1986; 6: 145-9.

5 Calin A. Rarity of nephropathy in ankylosing spondylitis. Arthritis Rheum 1982; 25: 1510.

6 Beukhof J R, Fleuren G J, Hoedemaeker P J, et al. IgA nephropathy: triumph of immunology or misconception? Neth J Med 1984; 27: 393-404.

SIR, We are grateful for the interest shown in our paper by Dr van de Laar and his colleagues.

The aim of our study was to obtain insight into a possible role of IgA containing immune complexes in the pathogenesis of ankylosing spondylitis and haematuria. Our data are not sufficient to report on the prevalence of $\operatorname{IgA}$ nephropathy in patients with ankylosing spondylitis. We agree that IgA nephropathy in ankylosing spondylitis is not a frequent diagnosis; several authors have reported a prevalence of $3 \%$ (range $0-5 \cdot 4 \%$ ). ${ }^{1-6}$ On the other hand, we think that the estimated prevalence of $0 \cdot 2-0.9 \%$ for $\operatorname{IgA}$ nephropathy in the Dutch population is too high. Tiebosch et al found an incidence of 19 per $10^{6}$ adults per year, ${ }^{7}$ and this indicates a prevalence below $0 \cdot 1 \%$. Similar data were reported in a study from France. ${ }^{8}$

We think that van de Laar et al underestimate their data and that more of their patients with ankylosing spondylitis may have $\operatorname{IgA}$ nephropathy. They defined haematuria as the presence of 10 or more red blood cells per high power field and this may be somewhat high. Haematuria in IgA nephropathy is often intermittent. The absence of macroscopic haematuria, proteinuria, purpura in combination with normal skin biopsies, normal renal function, and normal serum IgA by no means rule out IgA nephropathy.

Departments of Rheumatology

and *Nephrology,

A J PEETERS

University Hospital Leiden, A W L VAN DEN WALL BAKE* The Netherlands

$M$ L WESTEDT

\section{References}

1 Calin A. Rarity of nephropathy in ankylosing spondylitis. Arthritis Rheum 1982; 25: 1510.

2 Jones D W, Mansell M A, Samuell C T, Isenberg D A. Renal abnormalities in ankylosing spondylitis. Br J Rheumatol 1987; 26: 341-5.

3 Wall B A, Agudelo C A, Pisko E J. Increased incidence of recurrent hematuria in ankylosing spondylitis: a possible association with IgA nephropathy. Rheumatol Int 1984; 4: 27-9.

4 Chou C T, Lee C F, Shieh S D, Huang H W, Ho Y S. The significance of raised serum $\operatorname{IgA}$ in ankylosing spondylitis with IgA nephropathy. Journal of the Formosan Medical Association 1984; 83: 1232-7. 
5 Shu K H, Lian J D, Yang Y F, et al. Glomerulonephritis in ankylosing spondylitis. Clin Nephrol 1986; 25: 169-74.

6 Mittal V K, Malhotra K K, Bhuyan U N, Malaviya A N. Kidney involvement in seronegative spondarthritides. Indian J Med Res 1983; 78: 670-5.

7 Tiebosch A T M G, Wolters J, Frederik P F M, et al. Epidemiology of idiopathic glomerular disease: a prospective study. Kidney Int 1987; 32: 112-6.

8 Simon P, Ang K S, Bavay P, Cloup C, Mignard J P, Ramee M P. Glomérulonéphrite à immunoglobulines A. Epidémiologie dans une population de 250,000 habitants. Presse Med 1984; 13: $257-60$.

\section{Alterations in appendicular skeletal mass in patients with rheumatoid arthritis, psoriatic arthritis, and osteoarthritis}

SIR, Cooper $e t$ al in their recent article on skeletal mass in rheumatoid arthritis, psoriatic arthritis, and osteoarthritis stated that lumbar bone mass is reduced in rheumatoid arthritis, irrespective of corticosteroid treatment. ${ }^{1}$

For this statement they quoted, without any personal experience, one published reference. ${ }^{2}$ In our opinion, however, this statement does not reflect the results of other reports concerning lumbar bone mass in rheumatoid arthritis. From the same author as the one referred to by Cooper $e$ al there is a previous study of early rheumatoid arthritis, in which no diminution of bone mass could be shown when patients with rheumatoid arthritis were compared with controls. ${ }^{3}$ In our own study we found a normal lumbar bone mass when female, postmenopausal patients with rheumatoid arthritis were compared with controls matched for sex, age, and menopausal state, irrespective of corticosteroid treatment.

Moreover, when discussing the appendicular skeleton as measured by single photon absorptiometry the authors refer to 'one single study', whereas there are many studies of peripheral bone mass at the radial site in rheumatoid arthritis, treated with corticosteroids or not. ${ }^{4-11}$ Some authors report a decreased peripheral bone mass in rheumatoid arthritis while others do not.

As the assessment of bone mass in arthritis is difficult owing to a variety of interfering factors, such as sex, age, menopausal state, disease activity and duration, local destruction, treatment (especially corticosteroid treatment), I feel that the discussion should have been expanded, with a better use of the available publications and a discussion of current controversies.

Arthritis and Metabolic Bone

A VERSTRAETEN

Disease Research Unit,

K U Leuven, U Z. Pellenberg,

B-3041 Pellenberg,

Belgium

\section{References}

1 Cooper C, Poll V, McLaren M, Daunt S O'N, Cawley M I D. Alterations in appendicular skeletal mass in patients with rheumatoid, psoriatic, and osteoarthropathy. Ann Rheum $D i$. 1988; 47: 481-4

2 Sambrook P N, Eisman J A, Yeates M G, Pocock N A, Eberl S Champion G D. Osteoporosis in rhcumatoid arthritis: safety of low dose corticosteroids. Ann Rheum Dis 1986; 45: 950-3.

3 Sambrook P N, Ansell B M, Foster S, Gumpel J M, Hesp R으 Reeve J. Bone turnover in early rheumatoid arthritis. 2음 Longitudinal bone density studies. Ann Rheum Dis 1985; 44 $580-4$.

4 Verstraeten A, Dequeker J. Vertebral and peripheral bon mineral content and fracture incidence in postmenopausaês patients with rheumatoid arthritis: effect of low dose corticosteroids. Ann Rheum Dis 1986; 45: 852-7.

5 Christansen C, Rodbro P. Skeletal status in patients with rheumatoid arthritis. Acta Med Scand 1975; 198: 453-4. $\vec{\omega}$

6 D'Angelo A, Fabris A, Sartori L, et al. Mineral metabolism and bone mineral content in rheumatoid arthritis. Effect of cortico steroids. Clin Exp Rheumatol 1985; 3: 143-6.

7 Dequeker J, Wielandts L, Koentges D, Nijs J. The assessmento of bone loss in rheumatoid arthritis. Acta Rhumatologica 1980 4: 228-9.

8 Mueller M N. Effects of corticosteroids on bone mineral in rheumatoid arthritis and asthma. $A J R$ 1976; 126: 1300.

9 Nagant de Deuxchaisnes C, De Vogelaer J P, Esselinckx W et al. The effect of low dose glucocorticoids on bone mass in rheumatoid arthritis: a cross-sectional and longitudinal study using single photonabsorptiometry. In: Alvioli L, Gennari $\mathrm{C} \Omega$ Imbimbo $\mathrm{H}$, eds. Glucocorticoid effects and their biologica出 consequences. New York: Plenum Press, 1984: 209-39.

10 Als O S, Godfredsen A, Christiansen C. The effect of glucocorticosteroids on bone mass in rheumatoid arthritis patients. Influence of menopausal state. Arthritis Rheum $1 \% 5$ 28: $369-75$.

11 Als O S, Christiansen C, Hellesen C. Prevalence of decreasi bone mass in rheumatoid arthritis. Relation to inflammatory treatment. Clin Rheumatol 1984; 3: 201-8."

SIR, As Dr Verstraeten indicates studies of bone mass a市 different anatomical sites in rheumatoid arthritis have produced conflicting results, and we stated this in oup report. It was not our purpose to write an exhaustive review of published work but to highlight some of the inconsistencies, which are, quite naturally, open to various? interpretations. We reported our own measurements of appendicular bone mass in three different polyarthro $\overline{2}$ pathies and considered these to be of interest. Dio Verstraeten's comments on corticosteroid treated patients do not really apply in this context owing to the deliberate exclusion of such patients from our study.

Rheumatology Unit and C COOPER MRC Environmental Epidemiology Unit, M MCLARE Southampton General Hospital, Southampton SO9 4XY

S O'N DAUNE $M$ I D CAWLEN

Correction: Combined suppressive drug treatment in severe refractory rheumatoid disease: an analysis of the relative effects of parenteral methylprednisolone, cyclophosphac mide, and sodium aurothiomalate. In the paper by Drs $M$ Walters and M I D Cawley (Ann Rheum Dis 1988; 47! 924-9) we regret that the first line of the second paragraph of the Discussion was omitted. The first sentence of this paragraph should have read 'The mode of action of botio gold and MP in this situation is not clear'. 